\title{
COVID-19 and Pacific food system resilience: opportunities to build a robust response
}

\author{
Penny Farrell ${ }^{1}$ - Anne Marie Thow ${ }^{1} \cdot$ Jillian Tutuo Wate ${ }^{2} \cdot$ Nichol Nonga $^{3} \cdot$ Penina Vatucawaqa $^{4} \cdot$ Tom Brewer $^{5}$. \\ Michael K. Sharp ${ }^{5,6}$ • Anna Farmery ${ }^{5} \cdot$ Helen Trevena ${ }^{1}$ • Erica Reeve ${ }^{7} \cdot$ Hampus Eriksson $^{2,5} \cdot$ Itziar Gonzalez $^{4}$. \\ Georgina Mulcahy ${ }^{1} \cdot$ Jacob G. Eurich ${ }^{8,9} \cdot$ Neil L. Andrew $^{5}$
}

Received: 19 May 2020 / Accepted: 9 July 2020 / Published online: 20 July 2020

(C) International Society for Plant Pathology and Springer Nature B.V. 2020

\begin{abstract}
The unfolding COVID-19 pandemic has exposed the vulnerability of the Pacific food system to externalities and has had farreaching impacts, despite the small number of COVID-19 cases recorded thus far. Measures adopted to mitigate risk from the pandemic have had severe impacts on tourism, remittances, and international trade, among other aspects of the political economy of the region, and are thus impacting on food systems, food security and livelihoods. Of particular concern will be the interplay between loss of incomes and the availability and affordability of local and imported foods. In this paper, we examine some of the key pathways of impact on food systems, and identify opportunities to strengthen Pacific food systems during these challenging times. The great diversity among Pacific Island Countries and Territories in their economies, societies, and agricultural potential will be an important guide to planning interventions and developing scenarios of alternative futures. Bolstering regional production and intraregional trade in a currently import-dependent region could strengthen the regional economy, and provide the health benefits of consuming locally produced and harvested fresh foods - as well as decreasing reliance on global supply chains. However, significant production, processing, and storage challenges remain and would need to be consistently overcome to influence a move away from shelf-stable foods, particularly during periods when human movement is restricted and during post-disaster recovery.
\end{abstract}

Keywords Food security $\cdot$ Policy $\cdot$ Food systems $\cdot$ Pacific $\cdot$ COVID-19, pandemic

Electronic supplementary material The online version of this article (https://doi.org/10.1007/s12571-020-01087-y) contains supplementary material, which is available to authorized users.

Penny Farrell

penny.farrell@sydney.edu.au

Anne Marie Thow

annemarie.thow@sydney.edu.au

Jillian Tutuo Wate

J.Wate@cgiar.org

Nichol Nonga

Nichol.Nonga@fao.org

Penina Vatucawaqa

Penina.Vatucawaqa@fao.org

Tom Brewer

tbrewer@uow.edu.au

Michael K. Sharp

michaels@spc.int

Anna Farmery

afarmery@uow.edu.au
Helen Trevena

helen.trevena@sydney.edu.au

Erica Reeve

ereeve@deakin.edu.au

Hampus Eriksson

hampus@uow.edu.au

Itziar Gonzalez

Itziar.Gonzalez@ fao.org

Georgina Mulcahy

georgina.mulcahy@sydney.edu.au

Jacob G. Eurich

jacobeurich@ucsb.edu

Neil L. Andrew

nandrew@uow.edu.au

Extended author information available on the last page of the article 
The unfolding COVID-19 pandemic is a crisis with many faces. It has exposed the vulnerability of the Pacific food system to externalities and has had far-reaching impacts, despite the small number of cases recorded thus far. In many respects, COVID-19 has 'landed' in the 21 countries and territories of the region, more as a suite of social, economic and food security issues than as a health crisis per se. Although the pandemic has yet to fully reveal itself as a health crisis in the region, it has prompted national governments and regional development partners to develop mitigation and adaptation measures at a scale not previously experienced in the region.

Pacific Island Countries and Territories (PICTs) are striving to ensure that COVID-19 does not evolve into a health crisis. The measures adopted to mitigate this risk - notably restrictions on the movement of people within and among countries - have had severe impacts on tourism, remittances, and international trade, among other aspects of the political economy of the region. PICTs are food import- and remittance-dependent economies (Connell 2013), and many are heavily reliant on income from tourism (e.g. Fiji, French Polynesia, New Caledonia, Palau, Samoa) (Wood 2020). The cessation of tourism is expected to result in substantial losses to economies - forecast scenarios in the range of US\$1-2 billion regionally (Pacific Community 2020). Such losses are realized across many parts of national economies, including unemployment, business failure, and changed patterns in the production and distribution of food. Reliance on remittances is also high: across 11 PICTs, funds transferred from overseas kin account for an average of $9.7 \%$ of GDP (Pacific Community 2020). Some countries have already experienced substantial falls in remittances since the COVID-19 outbreak (Graue 2020).

National food systems in the Pacific region share attributes with those in other Small Island Developing States (SIDS). Much of their fragility is due to geographic remoteness, growing import dependence, and in many places, limited arable land and declining agriculture production (Fig. 1). The region experienced a dramatic decline in per capita domestic crop production up to the mid-1990s, which has not been recovered.

Staple foods, particularly rice and wheat, account for much of the volume of food imported to the region, but nutrient dense and sugary food and beverages are also rising markedly. These trends in the availability of foods over the past half century (Thaman 1982) are reflected in diets which have shifted from being high in locally grown fresh fruits and vegetables, seeds and nuts, lean meat and seafood, to diets high in processed and often imported foods (Thow et al. 2011). Consequently, the triple burden of malnutrition ${ }^{1}$ is a large and growing issue in the region (Global Nutrition Report 2018; Hughes and Lawrence 2005; Sievert et al. 2019) and

\footnotetext{
${ }^{1}$ The coexistence of undernutrition, overnutrition and micronutrient deficiencies.
}

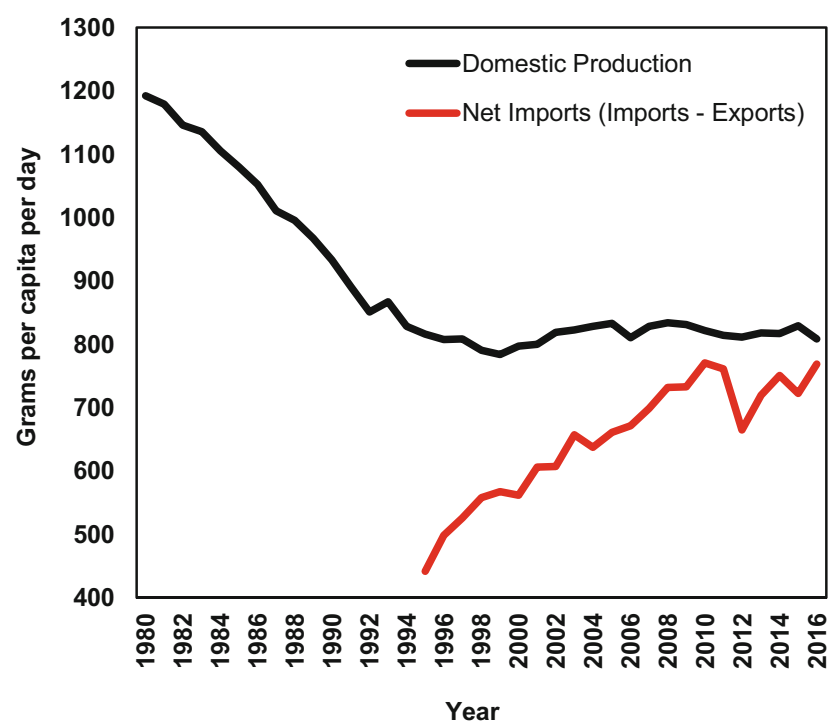

Fig. 1 Comparison of trends in food (crop) production and food trade, in grams, per capita per day. Domestic production data includes crops, excluding cash crops. Trade data (net imports) includes foods relevant to food security, excluding cash crops; tuna was also excluded due to uncertainty in estimates. See Supplementary materials for Fig. 1 for the list of: a foods included in the production and trade time series data and b) countries included in the presented annual mean production and trade estimates. Note, Fiji and Papua New Guinea were excluded due to their disproportionate influence on per capita estimates. Trade data derived from the Pacific Food Trade Database (Brewer et al. 2020). Crop production data downloaded from Food and Agriculture Organization of the United Nations (2020a). Population data sourced from Food and Agriculture Organization of the United Nations (2020b)

prevalence of diet-related non-communicable diseases are particularly high in PICTs (Anderson 2013).

These trends and events highlight the complexity of addressing the food security dimensions of the COVID-19 pandemic, in a landscape already challenged by processes and climate shocks that threaten economies and societies. In the last month, for example, Tropical Cyclone Harold swept through Solomon Islands, Vanuatu, Tonga, and Fiji in the midst of COVID-19 mitigation preparations, destroying houses and crops. The confluence of the cyclone and COVID-19 led to a tragic loss of life in the sea off the island of Malaita in Solomon Islands, as people travelled to their home villages from the capital (Kaukui 2020).

Even in the much-desired scenario that the region remains largely free of widespread infection, its impacts will manifest in many different ways (Table 1). The range of potential and actual impacts for food systems and food security in the Pacific region shown in Table 1 may be seen as a subset of those noted globally (Haddad et al. 2020a, b). Of particular concern will be the interplay between loss of incomes and the availability and affordability of local and imported foods. A disproportionate burden may fall on women and children as local availability and affordability of food is impacted through the closure of informal markets (Table 1). In Solomon Islands, 
Table 1 Summary of key potential food system impacts in the Pacific region

Global analysis of potential COVID-19 Pacific-specific food system context related impacts on food systems
Existing challenges in access to inputs, services, labour and finance; relatively long production cycles for root crops; data gaps in domestic production potential. restrictions on travel, reducing agricultural production, yields and income; access to services may be reduced (e.g. veterinary, extension services). Decreased demand and purchasing power will reduce investment and technology, further reducing availability. Seasonal impact needs to be considered.

Little global commentary on fisheries to date.

Restrictions on movement of people impacts seasonal agricultural workforce especially relevant for labour-intensive crops, such as fruits and vegetables. Higher vulnerability to COVID-19 for elderly farmers. Decreased ability for companies to care for workers health and wellbeing (across global supply chain).

Increased levels of post-harvest losses due to reduced workforce.

Processing Food companies (domestic and external) facing increased demand for processed staples may experience input shortages due to production and transport being affected. Small and Medium Enterprises (SMEs) at risk of bankruptcy.

Distribution Restricted international trade, including exports from some countries; air freight and shipping likely to be reduced; price increase in export (non-PICT) countries raising affordability concerns for PICTs; potential backlog at ports and airports during and post-crisis.

Impacts on internal trade and distribution due to reduced travel and quarantine measures, including restricted internal borders.

Food Fresh food markets reduced due to market restrictions on gatherings; food safety concerns (hygiene). Closure of farmers' markets and stalls for selling fresh fruit

Fish are the dominant animal-source food; Beche de mer is an important source of income for many rural communities.

Many Pacific Island Countries and Territories (PICTs) are remittance-dependent; seasonal agricultural labour to Australia and New Zealand is significant.

Regionally produced foods subject to high losses.

Limited domestic processing in PICTs and high dependence on imported inputs; village processing important for short distance/domestic distribution.

\section{All PICTs net-food-importers of staple (energy) foods.}

Common to have food transported between and within islands domestically; some reliance on public transport for food transport; kin networks important for sharing of food. Pacific is import-dependent for fuel.

Open markets major source fresh fruit and vegetables, meat etc.; hygiene and food safety may be an issue.

Potential food system, food security and nutrition impacts in Pacific

Increased demand for locally grown staples (e.g. root crops) if prices of imported commodities rise. Potential for increased participation in home gardening/own account production; even if production increases still variability in capacity, especially by geography and access to technologies; challenges to access inputs, services, labour and finance exacerbated.

Demand and domestic catch of fish may increase; probable major disruptions to regionally important tuna industry will impact on national access to tuna and economies.

Reduction in labour force mobility may contribute to declines in income, which can have direct implications for people's access to food; disease and limited health services will impair agricultural output in the instance of high disease rates. Population flows from urban to rural areas, e.g. people returning to home villages, may influence availability of local rural labour for agriculture.

Existing post-harvest losses potentially exacerbated due to supply chain disruptions; potential for investment in primary processing, local distribution.

Reduced availability / increased prices for domestically produced staples and food that is usually processed in-country; local processing of tuna disrupted; shortages of imported processed and packaged foods possible - both basic e.g. milk powder, tinned foods, and also highly processed foods (unhealthy discretionary foods). SMEs particularly affected.

Possible reductions in staple foods; shortages of imported processed and packaged foods possible (unhealthy discretionary foods); possibility to shorten supply chains including intra-regional trade.

Domestically produced food supply to urban centres reduced (e.g. root crops, fruit, vegetables); potential reductions in distribution of imported food to rural areas; likely differential impacts for producers (e.g. based on geographical location, own transport); home gardening won't be affected. Any disruptions to fuel imports could impact stove fuels for cooking.

Access to and consumption of fresh food may be reduced in urban areas; If livelihoods affected, food security and/or ability to purchase different food may be 
Table 1 (continued)

Global analysis of potential COVID-19 Pacific-specific food system context

related impacts on food systems
Potential food system, food security and nutrition impacts in Pacific and vegetables increase food waste and reduce farmers' ability to sell food and thus have a stable livelihood; reduce the ability of consumers to access fresh fruit and vegetables.

Potential supply concerns for supermarkets, may be price gouging; commodity prices could also fall due to a lack of demand. Types of foods consumed could change in response to change in prices.

Declines in food eaten away from home with physical/social isolation public health measures.

Informal food service significant in economy.

mall stores a major source of food in region; supermarkets important source of food in urban areas.

(econs.

Probable shift to long-shelf-life and staple foods with changed shopping behaviour due to physical distancing efforts; reduced consumption of fresh vegetables and other perishable products.

Food substitution and access issues will differentially impact women and children.
Limited storage capacities for fresh foods, particularly in low income areas.

Intra-household power dynamics very influential to food distribution in the Pacific region. affected; non-cash food economies likely to become more important in village economies; gendered impacts are evident from the restriction in informal marketing, with women and youths most commonly taking up economic activities for sale of subsistence produce in the margins of the formal economy.

Stores and supermarkets may be unable to source some stocks and prices may increase for goods in short supply. Differential impacts rural/urban and differences between PICTs; price gouging may impact food security.

Informal sector may be unable to access (physical/financial) food ingredients; SMEs likely to be particularly affected. Dietary changes both positive (reduced 'fast' food), and negative (reduced dietary diversity).

Greater consumption of staple and processed foods may exacerbate diet transition, mediated by availability, accessibility, affordability of the substitute food and dietary habits.

Increase in domestic violence and conflict within households could increase food insecurity for vulnerable groups.

Table derived from the Global Alliance for Improved Nutrition's 'The COVID-19 Crisis and Food Systems: probable impacts and potential mitigation and adaptation responses' (Haddad et al. 2020b), and informed by Aqorau 2020; Eriksson et al. 2020; Food and Agriculture Organization of the United Nations 2020c; Haddad et al. 2020a; High Level Panel of Experts on Food Security and Nutrition 2020; Husain et al. 2020; Wood 2020

for example, women comprise the majority of sellers in such markets now disrupted due to COVID-19 related restrictions, with knock-on effects on household and village economies (Eriksson et al. 2020). As market places are changing, traditional practices of bartering and sharing are also on the rise (Maclellan 2020). The existing challenges of agricultural production and a high degree of food import dependence within the region have the potential to exacerbate the impacts of COVID-19 responses. Given the nature of imported foods, it is not axiomatic that COVID-19 will lead to a reduction in the quality of diets.

Extreme necessity can be a time for positive policy innovation. Our summary (Table 1) identifies some potential positive intersections that could prompt re-visioning of aspects of the food system in the region. The great diversity among PICTs in their economies, societies and environments will be an important guide to planning interventions and developing scenarios of alternative futures. Papua New Guinea, Fiji, Solomon Islands, and other larger nations may envision futures with a resurgent agricultural base. In Solomon Islands, for example, growing conditions are favourable for a range of crops, and a majority of households are engaged in agriculture in some way on the estimated 1.1 million hectares of agricultural land in use (Solomon Islands National Statistics Office et al. 2019). Such a future is less plausible for the atoll nations of Micronesia where the production, trade, and consumption of fish, particularly tuna sourced through potentially very long supply chains, is more likely to be prominent.

Bolstering regional production and intraregional trade in a currently import-dependent region could strengthen the regional economy, and provide the health benefits of consuming locally produced fresh foods - as well as decreasing reliance on global supply chains. Significant production, processing and storage challenges remain and would need to be consistently overcome to influence a move away from shelf-stable foods, particularly during periods when human movement is restricted and during post-disaster recovery. Supply chains vary in complexity and vulnerability to disruption. Their ability to respond quickly will depend on many factors including characteristics of the food itself, resilience of the distribution chains, and a preparedness to change. There is an opportunity to adapt supply chains in response to COVID-19 by building 
on responses to climate change and natural disasters (Cvitanovic et al. 2016) which will mean supply chains are more resilient in the long-term. These include increasing coordination and transparency of food trade within the region (Steiner et al. 2020), particularly for root crops; ensuring access to finance and inputs to increase local production; better integration of local food producers into local and regional value chains; and increased local processing and packaging to reduce food waste (Table 1).

Enhancing storage, processing, and distribution of food commodities is vital in mitigating food and nutrition security impacts during the current crisis. For example, strengthening food storage and inter- and intra-island transport has been shown to increase consumption of fresh foods (and thus avert mortality and morbidity from diet-related non-communicable diseases) in Fiji (Snowdon et al. 2011). There may also be benefits to prioritising less perishable food (e.g. root crops) in Pacific supply chains, which lack adequate storage for more perishable items such as fish. Strengthening consumer demand has also been shown to enhance supply and demand systems and reduce post-harvest food waste (Underhill et al. 2017). Education for behaviour change has the potential to increase demand for locally produced foods (Cvitanovic et al. 2016; Vermeulen et al. 2019).

Working through COVID-19 may strengthen the ability of sectors to work together in more integrated ways; discussions around food and food systems must intersect with health and the environment (Bennett et al. 2020). For example, recent analysis from the UK on the impact of COVID-19 on food systems (Sharpe et al. 2020) has shown that "... government reactions to food supply issues exposed how increased coordination could aid responses and build trust in times of crisis, both now and in the future."

Before COVID-19 the Pacific food system had become increasingly vulnerable to shocks and other disruptions to the production, distribution and acquisition of food. It had become that way for a multitude of historical and contemporary reasons and was already threatened by climate change and other external threats. Like climate change, the pandemic was created somewhere else, but threatens the prosperity and wellbeing of Pacific people in profound ways. Unlike climate change, the resilient people of the Pacific regio can influence how this crisis plays out: whether it will catalyse change in the functioning of national food systems and their reliance on imported foods will be a critical issue in the coming years.

Acknowledgements Supported by funding from the Australian government through ACIAR project FIS/2018/155.

Availability of data and material Not applicable.

Code availability Not applicable.
Authors' contributions PF, AMT, ER, HA, HT, AF, TB, GM, IG, JE, NA wrote and reviewed the manuscript. PF, AMT, ER, HA, HT, AF, TB, GM, IG, NA, JW, MS, NN, PV contributed to Table 1, and the design and final review of the manuscript. JE, MS, TB and NA performed original analysis for Fig. 1.

Funding information Supported by funding from the Australian government through ACIAR project FIS/2018/155.

\section{Compliance with ethical standards}

Conflicts of interest/competing interests The authors declare no conflicts of interest

\section{References}

Anderson, I. (2013). The economic costs of non-communicable diseases in the Pacific Islands: A rapid Stocktake of the situation in Samoa, Tonga and Vanuatu. Washington DC: USA.

Aqorau, T. (2020). COVID-19 and its likely impact on the tuna industry in the Pacific Islands. DevPolicyBlog. Canberra, Australia: Development policy Centre, Australian National University.

Bennett, N. J., Finkbeiner, E. M., Ban, N. C., Belhabib, D., Jupiter, S. D., Kittinger, J. N., et al. (2020). The COVID-19 pandemic, small-scale fisheries and coastal fishing. Communities: Taylor \& Francis.

Brewer, T. D., Abbott, D., Lal, N., Sharp, M., Thow, AM., Andrew, N.L. (2020). A method for cleaning trade data for regional analysis: The Pacific Food Trade Database Version 1 (1995-2016). Pacific Community Working Paper. Noumea, New Caledonia: Pacific Community

Connell, J. (2013). Islands at risk? Environments, economies and contemporary change: Edward Elgar publishing.

Cvitanovic, C., Crimp, S., Fleming, A., Bell, J., Howden, M., Hobday, A., et al. (2016). Linking adaptation science to action to build food secure Pacific Island communities. Climate Risk Management, 11, 53-62.

Eriksson, H., Ride, A., Boso, D., Sukulu, M., Batalofo, M., Siota, F., Gomese, C. (2020). Changes and adaptations in village food systems in Solomon Islands: A rapid appraisal during the early stages of the COVID-19 pandemic. WorldFish program report: 2020-22. Penang, Malaysia.

Food and Agriculture Organization of the United Nations (2020a). FAOSTAT. http://www.fao.org/faostat/en/\#data/QC. Accessed 03/ 03/2020.

Food and Agriculture Organization of the United Nations (2020b). FAOSTAT. http://www.fao.org/faostat/en/\#data/QC. Accessed 05/ 04/2020.

Food and Agriculture Organization of the United Nations (2020c). Keeping food and agricultural systems alive - Analyses and solutions in a period of crises - COVID-19 Pandemic. http://www.fao. org/2019-ncov/analysis/en/. Accessed 27/04/2020.

Global Nutrition Report (2018). Appendix 3: Countries with significant multiple forms of malnutrition. https://globalnutritionreport.org/ reports/global-nutrition-report-2018/appendix-3-countriessignificant-multiple-forms-malnutrition/.

Graue, C. (2020). Families in Samoa struggle as seasonal workers can't send money home. In A. R. Australia (Ed.), Pacific Beat.

Haddad, L., Fanzo, J., Godfrey, S., Hawkes, C., Morris, S., Neufeld, L. (2020a). The COVID-19 crisis and food systems: Addressing threats, creating opportunities. https://www.gainhealth.org/media/ news/covid-19-crisis-and-food-systems-addressing-threatscreating-opportunities. Accessed 06/04/2020. 
Haddad, L., Fanzo, J., Godfrey, S., Hawkes, C., Morris, S., Neufeld, L. (2020b). The COVID-19 crisis and food systems: Probable impacts and potential mitigation and adaptation responses. https://www. gainhealth.org/sites/default/files/news/documents/covid-19-crisisand-food-systems-probable-impacts-and-potential-mitigation-andadaptation-responses.pdf. Accessed 06/04/2020.

High-Level Panel of Experts on Food Security and nutrition (HLPE). (2020). Interim issues paper on the impact of COVID-19 on food security and nutrition (FSN). Rome, Italy: Committee on World Food Security.

Hughes, R., \& Lawrence, M. (2005). Review article: Globalisation, food and health in Pacific Island countries. Asia Pacific Journal of Clinical Nutrition, 14(4), 298-306.

Husain, A., Sandström, S., Greb, F., Groder, J., \& Pallanch, C. (2020). COVID-19: Potential impact on the world's poorest people. Rome, Italy: A WFP analysis of the economic and food security implications of the pandemic.

Kaukui, I. (2020). MV Taimareho: Sea tragedy.

Maclellan, N. (2020). Smart harvest. https://insidestory.org.au/smart-harvest/.

Pacific Community (2020). Economic and Social Vulnerability to COVID. https://sdd.spc.int/disasters-data/covid-19.

Sharpe, R., Parsons, K., \& Hawkes, C. (2020). Coordination must be key to how governments respond to Covid-19 food impacts: A view from England. Rethinking Food Governance Guidance Note. London: United Kingdom.

Sievert, K., Lawrence, M., Naika, A., \& Baker, P. (2019). Processed foods and nutrition transition in the Pacific: Regional trends, patterns and food system drivers. Nutrients, 11(6). https://doi.org/10.3390/nu11061328.

Snowdon, W., Moodie, M., Schultz, J., \& Swinburn, B. (2011). Modelling of potential food policy interventions in Fiji and Tonga and their impacts on noncommunicable disease mortality. Food Policy, 36(5), 597-605.

Solomon Islands National Statistics Office, Ministry of Finance and Treasury, Ministry of Agriculture and Livestock, \& in collaboration with the Food and Agriculture Organization of the United Nations and the World Bank. (2019). Report on National Agriculture Survey 2017. Solomon Islands: Honiara.

Steiner, R., Ruben, D., Milani, P., \& Ehsani, M. (2020). Blog 16: Five COVID-19 reflections from a food system perspectives-And how we could take action. Geneva, Switzerland: Nutrition Connect.

Thaman, R. R. (1982). Deterioration of traditional food systems, increasing malnutrition and food dependency in the Pacific Islands. Journal of food \& nutrition

Thow, A. M., Heywood, P., Schultz, J., Quested, C., Jan, S., \& Colagiuri, S. (2011). Trade and the nutrition transition: Strengthening policy for health in the Pacific. Ecology of Food and Nutrition, 50(1), 1842.

Underhill, S. J., Zhou, Y., Sherzad, S., Singh-Peterson, L., \& Tagoai, S. M. (2017). Horticultural postharvest loss in municipal fruit and vegetable markets in Samoa. Food Security, 9(6), 1373-1383.

Vermeulen, S., Park, T, Khoury, CK, Mockshell, J, Béné, C, Thi, HT, Heard, B, Wilson, B, (2019). Changing diets and transforming food systems. CCAFS Working Paper no. 282. Wageningen, the Netherlands: CGIAR research program on climate change, agriculture and food security (CCAFS).

Wood, T. (2020). What will COVID-19 mean for the Pacific: A problem in four parts. DevPolicyBlog. Canberra, Australia: Development policy Centre, Australian National University.

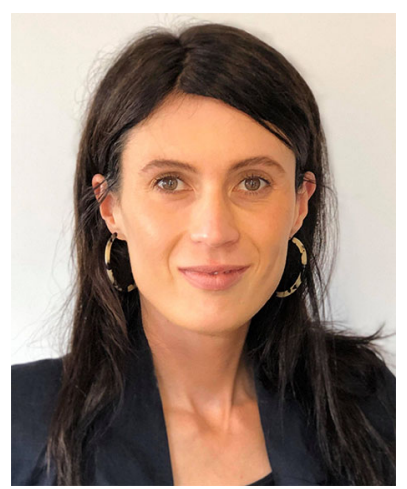

Dr. Penny Farrell is a public health researcher and veterinarian with over seven years of experience in health, nutrition, and agriculture policy research in Pacific Island Countries, Asia, and Africa. Penny recently completed a $\mathrm{PhD}$ on food security in the Pacific region and has worked previously in the not-for-profit, university, and government sectors. Penny currently holds a position as a Research Fellow at The University of Sydney dedicated to researching how to build healthy and sustainable food systems globally, with a focus on low income settings.

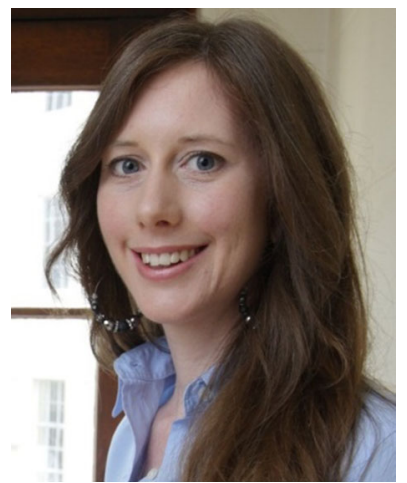

Dr. Anne Marie Thow is an Associate Professor in Health Policy at the University of Sydney. Her research uses theories of public policy making to explore facilitators and barriers to best practice public health nutrition policy, with a particular focus on the interface between economic policy and nutrition. Anne Marie currently collaborates on research in Asia, Africa and the Pacific, designed to strengthen nutrition policy making, and regularly consults with international agencies regarding nutrition policy, including the World Health Organization, Food and Agriculture Organization and International Food Policy Research Institute. Prior to her PhD, Anne Marie worked for the Governments of Australia and Fiji on nutrition policy issues. She trained in nutrition and has a Masters in Public Policy and Economics.

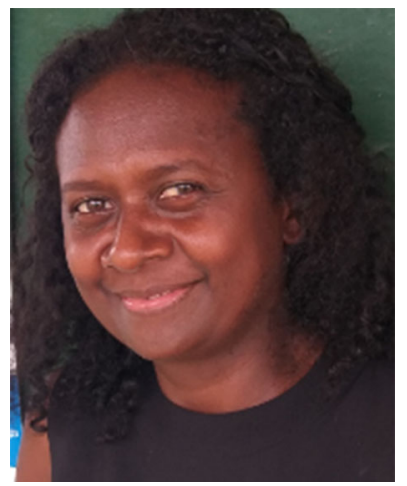

Dr. Jillian Tutuo Wate is a nutritionist by profession with over 5 years of experience in public health research and nutritionrelated policy intervention for the prevention of obesity and noncommunicable diseases in the Pacific. She has led the assessment and monitoring work for food environments in the Pacific under the Pacific Research Center for Prevention of Obesity and Non-communicable Diseases (CPOND). She is currently a Research Fellow with WorldFish, an International Non-Governmental Organisation researching on ways to promote food and nutrition security in the Pacific food system to address the double burden of malnutrition in Solomon Islands and Vanuatu. She is based in Honiara, Solomon Islands and has contributed to a range of multi-sectoral nutrition-related policies and research. 


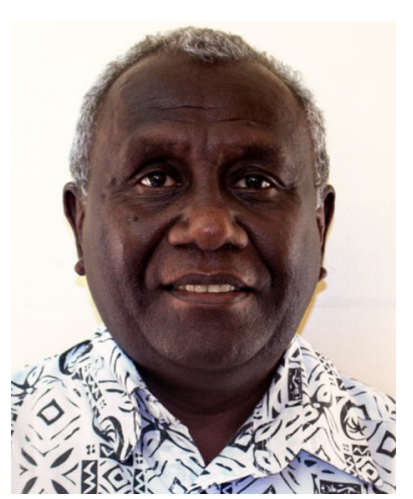

Mr. Nichol NONGA holds a Bachelor in Rural Techniques (Animal Production), University of Queensland; Diploma in Rural Techniques (Animal Production), Queensland Agriculture College, a Certificate in Veterinary clinic and laboratory techniques, University of Queensland, Australia. Mr. Nichol NONGA is currently the National Policy Officer (FIRST) Solomon Islands, Food and Agriculture Organisation (FAO), assisting the SIG developing policies on Food and Nutrition Security (2017-2020). In 2007-2016, held the position of Animal Production Specialist, Animal Health \& Production Thematic Group, The Pacific Community (SPC), providing technical assistance and advice on animal production, climate change and as the regional focal point for Animal Genetic Resources for FAO in the Pacific. Mr. Nichol NONGA is a Solomon Islander, faithfully served the Solomon Islands Government for 30 years holding various positions and finally as Director of Livestock and Veterinary Services Division, Ministry of Agriculture \& Livestock, Solomon Islands, 2004-2007.

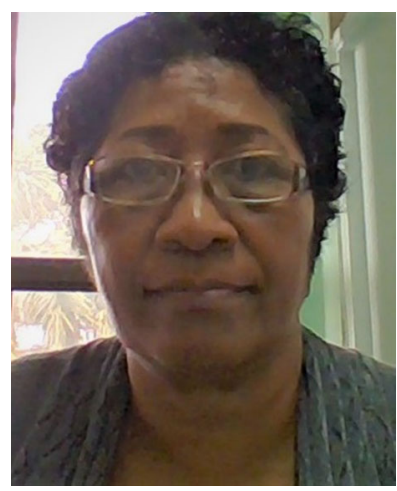

Ms. Penina Vatucawaqa is a National Policy Officer in Food and Nutrition Security with the Food and Agriculture Organisation (FAO) working for the Food and Nutrition Security, Impact, Resilience, Sustainability and Transformation (FIRST) Project in Fiji. Her work with FAO FIRST includes providing government with policy assistance and capacity development in support of improved food security, nutrition and sustainable agriculture in Fiji. Ms. Vatucawaqa has also had a wide experience in conducting nutrition research such as National Nutrition Surveys and Food Balance Sheets (a tool for assessing food availability) that has been used for developing policies in the country.

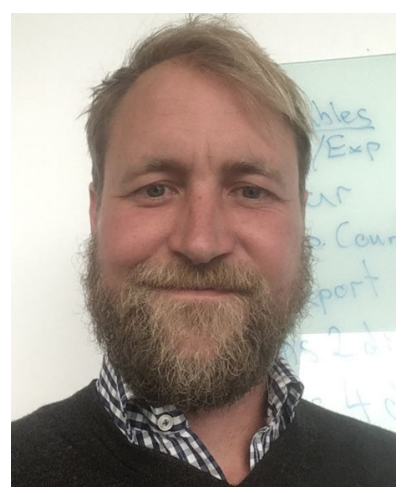

Dr. Tom Brewer is an interdisciplinary scientist with training in marine ecology and $\mathrm{Ph} \mathrm{D}$ in environmental sociology. He has been working in the Pacific for over a decade on natural resource management and human development challenges. His primary skill is in integration of diverse data sources to answer complex socialecological questions relating to resource sustainability and human wellbeing. Tom is currently part of a team focused on improving food systems in the Pacific (ACIAR FIS-

2018-155). His primary role is in developing a database of food and beverage trade for the Pacific to better understand the influence of food trade in macroscale food consumption patterns and non-communicable diseases such as obesity and diabetes.

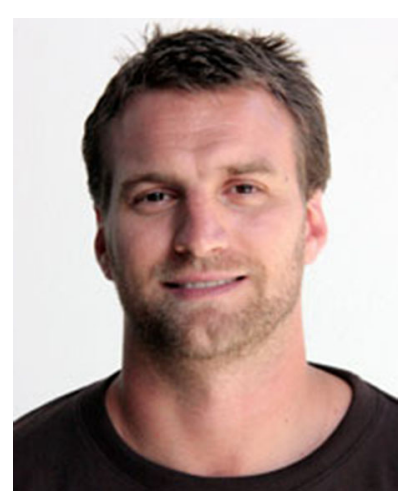

Mr. Michael K. Sharp is an Economic Statistics and Microdata Specialist at the Pacific Community (SPC). Mike has worked at SPC for 9-years where he has supported 22 Pacific Island countries and territories (PICTs) to collect, compile and analyse development microdata, which range from fisheries and agricultural to nationally representative census and survey data. His research interests mainly surround survey methodology to extend the use of household income and expenditure survey data to conduct poverty, food security and nutrition analysis in order to form an evidence base to address hardship and malnutrition in the Pacific region. Mike previously conducted fieldwork in Vanuatu and Guyana and he was employed in the Australian financial sector. He holds a master's degree in economics and a bachelor's degree in agricultural economics. Mike is an Honorary Fellow with the Faculty of Law, Humanities and the Arts, University of Wollongong.

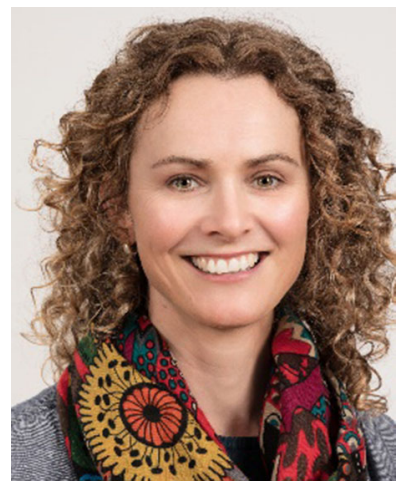

Dr. Anna Farmery is a Vice Chancellor's Post-Doctoral Research Fellow at the Australian National Centre for Ocean Resources and Security (ANCORS) at the University of Wollongong in Australia. Her research is focussed on the integration of food and nutrition security considerations in ocean and fisheries governance, and on ways to improve the overall contribution of seafood to food and nutrition security in terms of sustainable, equitable and rational resource use. She has published articles on issues of seafood sustainability and fisheries management, and on the integration of fish and food policies. Anna has worked on aspects of sustainable food systems, in agriculture and fisheries, for over 20 years and is currently investigating value chains and Pacific food systems.

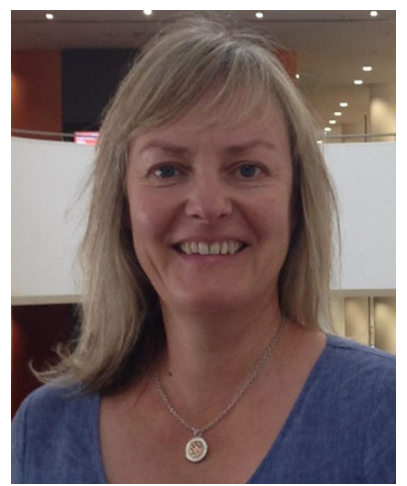

Dr. Helen Trevena has experience of working in the business, non-government, and government sectors in operational, consulting and policy roles. She is currently an Early Career Research Fellow at the Menzies Centre for Health Policy where her research interest is policy to deliver a healthier food supply. Helen is supported by a co-funded National Health and Medical Research Council and Heart Foundation Early Career Fellowship. 


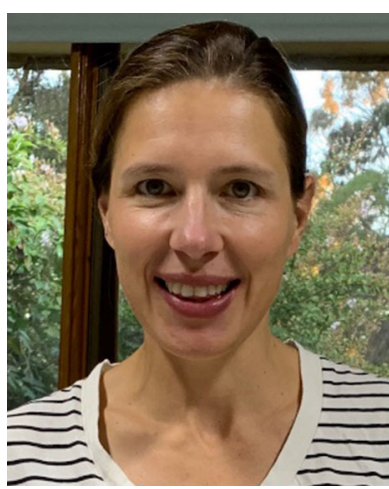

Ms. Erica Reeve is a PhD candidate with GLOBE at Deakin University. She has over 17 years of work experience in public health nutrition in the Asia Pacific region and remote Australian indigenous communities which includes extensive experience working with and consulting to national governments and international organisations. She has experience in strategic policy development, stakeholder engagement, programme planning, health promotion and highlevel advocacy, particularly as applied to diets, NCDs reduction, and maternal and child nutrition.

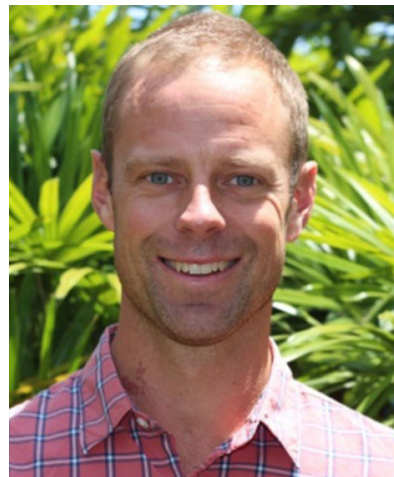

Dr. Hampus Eriksson is a systems ecologist. He is the Senior Scientist at WorldFish, a CGIAR centre, in Solomon Islands and an Associate Professor at the Australian National Centre for Ocean Resources and Security (ANCORS) at the University of Wollongong in Australia. His research focuses on rural development through fish-based livelihoods; testing and evaluating innovations that enhance fish-based livelihoods in small-scale fisheries. The research is implemented through cross-disciplinary collaborations in the academic and fisheries sector in the Pacific Islands, Southeast Asia and Africa.

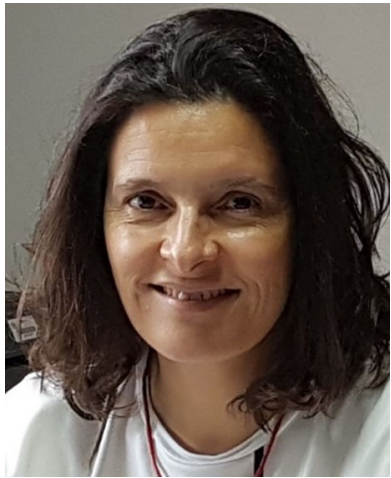

Ms. Itziar Gonzalez joined FAO in February 2016 as a policy officer for Food Security, Nutrition and Sustainable Agriculture, working first in Sri Lanka and then in three Pacific countries Vanuatu, Solomon Islands and Fiji. Prior to this position, Itziar spent over 20 years implementing and providing technical advice to rural development initiatives in different countries of South and Central America and the Caribbean. During these years, she was involved in different

Development initiatives from the United Nations, the Spanish Agency for International Development Cooperation, and some Spanish NGOs, amassing knowledge on different areas of expertise, as integral farming, food systems and nutrition sensitive agriculture, community forestry or artisanal fisheries and aquaculture. She is an agricultural engineer from the Polytechnic University of Madrid, Spain and obtained an MSc in Management of Agro-ecological Knowledge and Social Change from the University of Wageningen, The Netherlands in 2005.

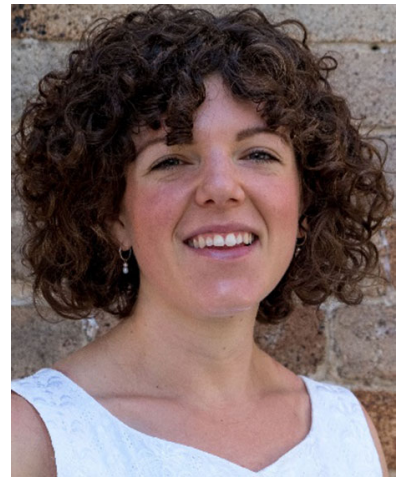

Ms. Georgina Mulcahy is a Research Assistant at the Menzies Centre for Health Policy, University of Sydney, providing policy analysis and research support to food systems policy projects across SubSaharan Africa, Asia and the Pacific. Georgina holds a Master of Sustainability, University of Sydney, and has 7 years' experience working in health as an Exercise Physiologist, namely management of diet-related noncommunicable diseases.

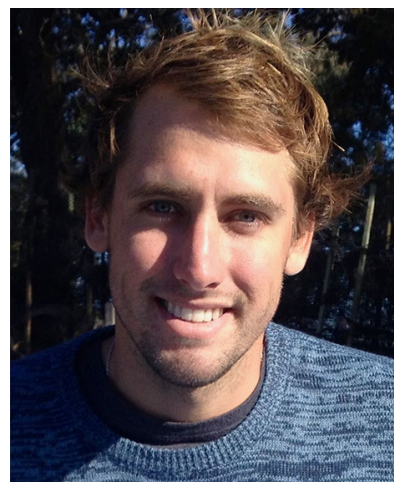

Dr. Jacob Eurich is a Postdoctoral Scholar at the Marine Science Institute at University of California, Santa Barbara. In 2018 he obtained his $\mathrm{PhD}$ from James Cook University and the Australia Research Council Centre of Excellence for Coral Reef Studies. He worked from Papua New Guinea to the Great Barrier Reef studying reef fish population and community responses to changes in habitat structure and coral bleaching. His research now focuses on the interactions between coral reefs and human communities in the Pacific region under the overarching themes of climate change, human use and resilience. Specifically, how much coral reef-derived foods matter to human health and the effective reef management practices that lead to levels and types of seafood consumption that promote human nutrition.

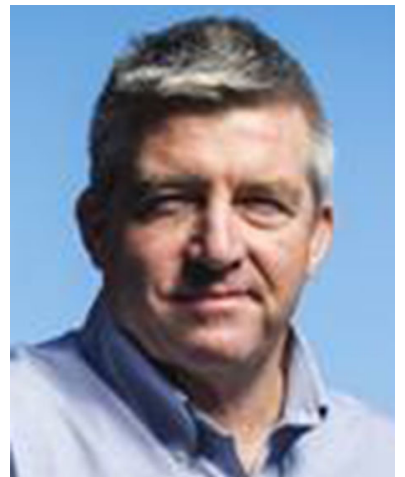

Neil Andrew is a Professor at the Australian National Centre for Australian National Centre for Ocean Resources and Security (ANCORS) at the University of Wollongong. He has worked at the interface between fisheries and ecological research and policy for more than 30 years in a wide range of contexts, including in Australia, New Zealand, Zambia, Malawi and in the Pacific region. Before joining ANCORS he worked as the global program leader in small-scale fisheries at the CGIAR Centre, WorldFish, based in Penang, Malaysia Professor Andrew is widely published in fisheries and ecology. 


\section{Affiliations}

Penny Farrell ${ }^{1}$ - Anne Marie Thow ${ }^{1} \cdot$ Jillian Tutuo Wate ${ }^{2} \cdot$ Nichol Nonga $^{3} \cdot$ Penina Vatucawaqa $^{4} \cdot$ Tom Brewer $^{5}$. Michael K. Sharp ${ }^{5,6}$ - Anna Farmery ${ }^{5}$ Helen Trevena ${ }^{1} \cdot$ Erica Reeve $^{7} \cdot$ Hampus Eriksson $^{2,5} \cdot$ Itziar Gonzalez $^{4}$. Georgina Mulcahy ${ }^{1} \cdot$ Jacob G. Eurich ${ }^{8,9} \cdot$ Neil L. Andrew ${ }^{5}$

1 Menzies Centre for Health Policy, Level 2, Charles Perkins Centre (D17), Sydney School of Public Health, The University of Sydney, Sydney, NSW 2006, Australia

2 WorldFish, Honiara, Solomon Islands

3 Food and Agriculture Organization of the United Nations (FAO), Honiara, Solomon Islands

4 Food and Agriculture Organization of the United Nations (FAO), Suva, Fiji
5 Australian National Centre for Ocean Resources and Security, University of Wollongong, Wollongong, Australia

6 Pacific Community, Noumea, New Caledonia

7 Global Obesity Centre, Institute for Health Transformation, Faculty of Health, Deakin University, Geelong, Australia

8 Marine Science Institute, University of California Santa Barbara, Santa Barbara, CA, USA

9 Department of Ecology, Evolution and Marine Biology, University of California, Santa Barbara, Santa Barbara, CA, USA 